FINAL REPORT

U. S. Department of Energy

\title{
FUNDAMENTAL CHEMISTRY AND THERMODYNAMICS OF HYDROTHERMAL OXIDATION PROCESSES
}

\author{
Principal Investigator: J. M. Simonson \\ Institution: Oak Ridge National Laboratory \\ Collaborators: R. E. Mesmer, J. G. Blencoe, and S. Dai \\ Institution: Oak Ridge National Laboratory \\ Collaborators: P. T. Cummings and A. A. Chialvo \\ Institutions: Oak Ridge National Laboratory and the University of Tennessee, Knoxville
}

Project Number: 55276

Project Duration: 1 September 1996 - 1 January 2001 


\section{Table of Contents}

Executive Summary

$\begin{array}{ll}\text { Research Objectives } & 1\end{array}$

Methods and Results $\quad 2$

Relevance, Impact and Technology Transfer $\quad 9$

$\begin{array}{ll}\text { Project Productivity } & 10\end{array}$

$\begin{array}{ll}\text { Personnel Supported } & 10\end{array}$

$\begin{array}{ll}\text { Publications } & 10\end{array}$

$\begin{array}{ll}\text { Interactions } & 13\end{array}$

$\begin{array}{ll}\text { Transitions } & 13\end{array}$

$\begin{array}{ll}\text { Patents } & 14\end{array}$

$\begin{array}{ll}\text { Future Work } & 14\end{array}$

$\begin{array}{ll}\text { Literature Cited } & 14\end{array}$ 


\section{Executive Summary}

The goal of this project was to address issues of fundamental chemistry and thermodynamic properties that currently limit the applicability of hydrothermal oxidation processes to the treatment of hazardous and radioactive DOE wastes. The primary issues are related to corrosion, in which materials of reactor construction are attacked by components of the process stream, and solids deposition, which can lead to local increases in corrosion damage or to fouling of the reactor. In addition to these general concerns, process problems may arise through precipitation of radioactive solids (e.g., actinides) during treatment of DOE aqueous mixed wastes.

Three coordinated approaches were used in this project to address these issues. First, the possibility of precipitating actinide-bearing solid phases from a process stream was addressed through measurements of the solubility of uranium oxide and carbonate phases at elevated temperatures. Further concerns of phase behavior in the reactor were addressed through measurements of the fluid density and phase boundaries of (water + gas) mixtures at high temperatures and pressures. Finally, efforts were made toward a more systematic and reliable assessment of the corrosivity of solutions through molecular-based studies of aqueous acids and salts using computer simulation techniques.

Major accomplishments of this work included improved delineation of the phase boundaries of (water + gas) mixtures at high temperatures, new information on the phase behavior of uraniumcontaining solid phases in equilibrium with aqueous solutions at elevated temperatures, and advances in our understanding of the reactions of salts and acids at high temperature which strongly affect the extent of corrosion. The impact of this work on DOE waste remediation 
technologies will depend on future decisions regarding the use of hydrothermal oxidation for treating aqueous wastes, particularly as an alternative to incineration. The techniques and analysis methods used in this project will be directly applicable to anticipated process conditions if this technology is accepted for field application. Near-term application of the results of this program are more probable in non-DOE applications such as hydrothermal processing of defense-related materials where deployment of this technology is anticipated in the near term.

Collaborative efforts in this work centered on simulation studies of molecular-level reactions in solution at high temperature, where extensive collaborations between researchers at Oak Ridge National Laboratory and at the University of Tennessee, Knoxville, resulted in significant progress toward an understanding of solution properties based on fundamental interactions. 


\section{Research Objectives}

Hydrothermal oxidation (HTO) is a promising technology for the treatment of aqueous-fluid hazardous and mixed waste streams. Waste streams identified as likely candidates for treatment by this technology are primarily aqueous fluids containing hazardous organic compounds, and often containing inorganic compounds including radioisotopes (mixed wastes). These wastes are difficult and expensive to treat by conventional technologies (e.g. incineration) due to their high water content; in addition, incineration can lead to concerns related to stack releases. An especially attractive potential advantage of HTO over conventional treatment methods is the total containment of all reaction products within the overall system.

The potential application of hydrothermal oxidation (HTO) technology for the treatment of DOE hazardous or mixed wastes has been uncertain due to concerns about safe and efficient operation of the technology. In principle, aqueous DOE wastes, including hazardous and mixed waste, can be treated with this technology. Oxidation reactions are carried out in the aqueous phase at high temperatures $\left(\sim 600^{\circ} \mathrm{C}\right)$, effectively converting organic waste constituents to nonhazardous materials (e.g., $\mathrm{CO}_{2}$ ). Inorganic materials which become insoluble in supercritical water may precipitate as scales adhering to components of the reactor, limiting reactor availability and necessitating frequent cleaning of the system. Also, most hazardous organic compounds contain heteroatoms (other than carbon, hydrogen, and oxygen). These heteroatoms, including halides $(\mathrm{F}, \mathrm{Cl}, \mathrm{Br}, \mathrm{I})$, sulfur, phosphorous, and some nitrogen groups, form strong mineral acids on oxidation of the organic compounds, resulting in a solution having low $\mathrm{pH}$ and high oxidation potential. This combination, in conjunction with the high temperatures and high fluid densities attained in both the heating and cooling regions of an HTO reactor, can lead to corrosion of structural materials (usually metals) anticipated for use in HTO reactor construction.

Methods have been suggested for mitigating the problems arising from the production of mineral acids and insoluble solids in HTO processes (Barnes et al., 1993). Previous work in this Laboratory centered on the problems arising from the presence of corrosive or insoluble inorganic compounds in HTO fluids (Simonson et al., 1993, 1994, 1995). However, significant gaps in our knowledge of process chemistry remained at the initiation of this project. It was not possible to determine accurately the properties of coexisting fluid phases; the solubilities of radioactive components of mixed wastes were unknown at high temperatures; and molecularlevel understanding of interparticle interactions was needed for reliable extrapolation of phenomenological equations for solution behavior beyond the range of experimental results. The present project was undertaken to address these deficiencies.

The project was undertaken to provide fundamental information needed to support deployment decisions related to HTO technology, and no innovations in the technology per se were anticipated. Rather, the innovations of this project involved applying new or existing experimental and modeling approaches to studies of aqueous inorganic reactions and properties under the rigorous anticipated HTO operating conditions. This work was made possible in part through the support of researchers at ORNL and the University of Tennessee, Knoxville, by the Division of Chemical Sciences, Geosciences and Biosciences, Office of Basic Energy Sciences of the Department of Energy. This support has allowed significant, unique experimental and 
computational resources to be developed for studies of aqueous solution chemistry at high temperatures and pressures.

\section{Methods and Results}

In this project we addressed three significant issues which potentially limit or preclude the application of hydrothermal oxidation (HTO) technology for treating DOE hazardous and mixed wastes. The issues included the lack of a suitable process model valid over the full range of temperature in HTO operation, an insufficient knowledge of (liquid + vapor) phase behavior at high temperatures, and concerns over reactor fouling through precipitation of inorganic scales. The approaches adopted to address these issues were:

- Developing molecular-based approaches to the description of aqueous solution chemistry at high temperatures and pressures, with a view toward understanding the relationships between molecular-level interactions and the observed large changes in thermodynamic and physical properties of aqueous solutions;

- New, precise measurements of the density and phase relationships at high temperatures in aqueous mixtures including noncondensible gases, with emphasis on the system $\left(\mathrm{H}_{2} \mathrm{O}+\mathrm{CO}_{2}\right.$ $+\mathrm{N}_{2}$ ) over wide pressure and composition ranges, and;

- Investigation of the solid-liquid phase behavior of materials specific to DOE applications of HTO technology (e.g., actinides) and of compounds which show promise as neutralizing agents to reduce or eliminate corrosion of reactor components at high temperatures.

Results in these areas are briefly described here; more complete descriptions are available in the listed publications resulting from this project.

\section{Molecular-based formalism and simulation of infinitely dilute hydrothermal systems.}

Conditions encountered in HTO processing extend from ambient to high temperatures (25 to $600^{\circ} \mathrm{C}$ ) at relatively high pressures (above 250 bars). This range includes the critical temperature of water $\left(374^{\circ} \mathrm{C}\right)$ near the critical pressure of 221 bars. Even for such thoroughly studied "simple" aqueous systems as sodium chloride solutions (cf. Pitzer et al., 1984; Anderko and Pitzer, 1993), there is no model for thermodynamic properties and phase equilibria which can be used reliably across all process conditions. This is due in large part to the fundamental change in species distribution of the solute which occurs as the system changes from essentially ionic dissolution at low temperatures to predominantly ion-paired solutes above the solvent critical point. In addition, near the solvent critical point many thermodynamic properties change rapidly with changes in temperature, pressure or solution concentration. This temperature range, from about 300 to $400^{\circ} \mathrm{C}$, is particularly important in HTO processing as corrosion and solids deposition problems tend to be most pronounced under these conditions (Thomason and Modell, 1984). Developing reliable representations for solution properties in this important region is complicated by the rapid changes in density and solute speciation, and the propagation of solvation effects over increasing distances in solution as the critical point is approached. Our efforts in the molecular-based description of solutions in the near-critical region have been 
driven by the need to develop a sound fundamental basis for the description of solution properties which can be extended over the full range of conditions of interest in HTO process applications.

The first objective of our study has been the fundamentally-based interpretation and understanding of high-temperature solvation of species over a wide range of molecular asymmetries, including imperfect gases, ionic, polar and nonpolar compounds. Molecular asymmetry, the difference in intermolecular interactions among species, is the actual origin of solution non-ideality. Asymmetry typically translates into pronounced gradients of solvent properties near charged species, and gives rise to electrostriction and dielectric saturation phenomena which render traditional solvation approaches inadequate (Chialvo, Cummings et al., 1999). An essential, and frequently overlooked, ingredient in the description of hydrothermal solutions is the coexistence of microscopic processes with rather different length scales, i.e., short-ranged phenomena associated with the solvation of species, and long-ranged phenomena associated with the compressibility of the medium (Chialvo and Cummings, 1994). Unless these phenomena are taken explicitly into account, any resulting modeling effort will be hindered by the presence of potentially divergent quantities that obscure the solvation behavior of species in the compressible environment (solvent).

For that purpose we targeted the unambiguous characterization of the solvation process by making rigorous connections between the solvation driving-force, the solvent microstructural changes around species, and the relevant macroscopic properties. This characterization has been done in several equivalent ways by interpreting the driving force of the solvation process, in terms of the finite perturbation of the structure of the solvent when a solvent molecule is replaced
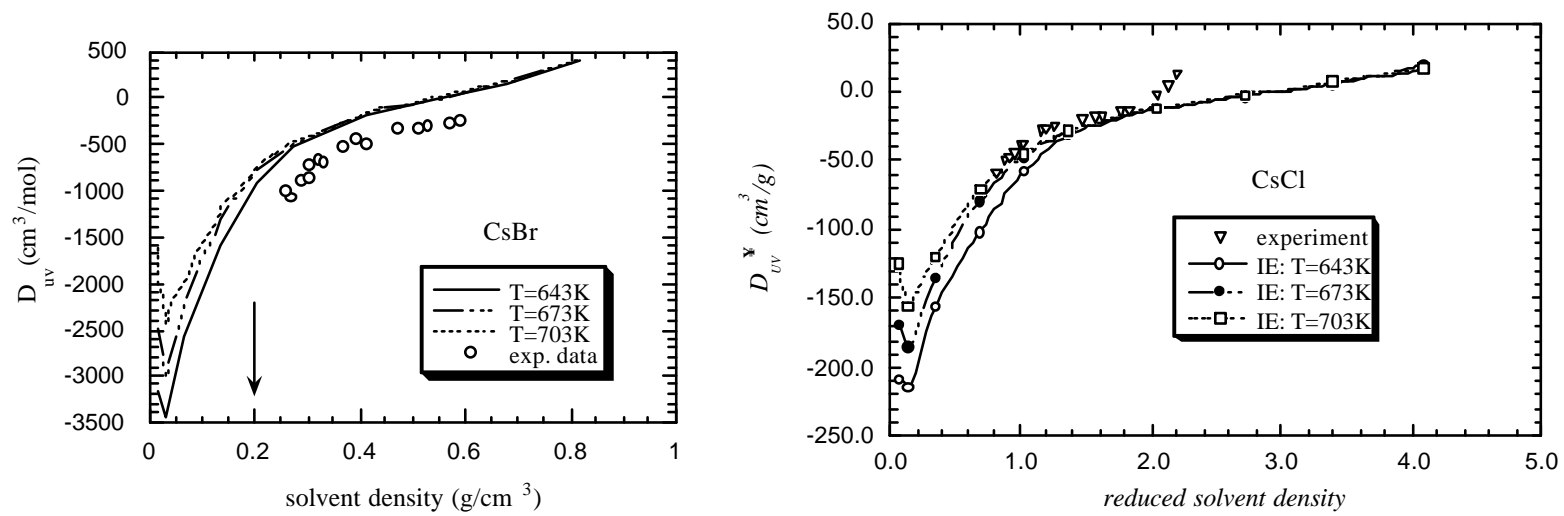

Figure 1. Density/temperature dependence for the regression quantity $D_{U V}$ of two aqueous solutions of cesium salts. A comparison between experimental data of Gruszkiewicz and Wood (1997) and integral equation calculations (Chialvo, Kusalik et al., 2001).

by a solute species (Chialvo, Kusalik et al., 2000). This perturbation has been rigorously linked to meaningful macroscopic quantities, such as the rate of change of pressure upon the addition of a solute species at constant temperature and density (which becomes Kritchevskii's parameter at solvent criticality), or an unambiguous definition of solvation number that does not depend on any choice of solvation shell radius (Chialvo, Kusalik et al., 2001). All these quantities are rigorously related to one another, such that the knowledge of one of them allows us to 


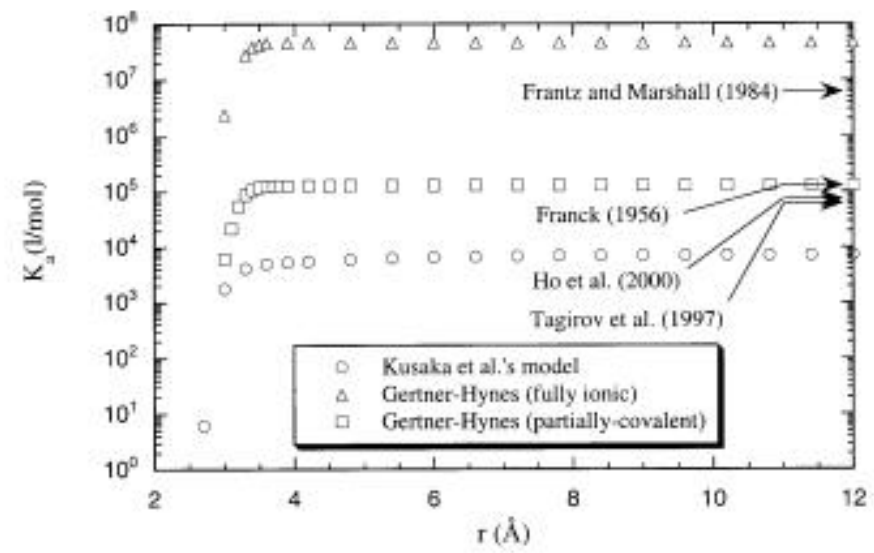

Figure 2. Comparison between experimental data (references as listed) and simulation results for three $\mathrm{HCl}$ models at a near-critical condition (Chialvo et al., 2000). reconstruct the complete solvation thermodynamic picture for the system under consideration, and most importantly, they can be determined from experimental measurements. A typical example is given in Figure 1 where we compare the predicted behavior of the quantity $D_{U V}=\left(\kappa^{I G} / \kappa\right) \bar{\nu}_{U}^{\infty}$, (the product between the solute partial molar volume and the ratio of isothermal compressibilities between the ideal gas solvent and the real solvent). This quantity has been introduced by Wood and colleagues (Wood, 1997) as an

empirical way to cancel the potential divergence in $\bar{v}_{U}^{\infty}$, and thus, to facilitate the regression of experimental data (Gruszkiewicz and Wood, 1997). The interesting feature of this quantity is the unexpected lack of temperature dependence for supercritical conditions, a behavior confirmed by our integral equation calculations, and microscopically interpreted through the solvation formalism (Chialvo, Cummings et al., 2000; Chialvo, Kusalik et al., 2000; 2001).

The second goal of our investigation of hydrothermal systems has encompassed the molecularbased determination of the ion-pair association constant via potential of mean force calculations, the interpretation of the properties based on microstructural details, the direct comparison between the simulation results and the corresponding experimental data. After our exploratory studies on $\mathrm{NaCl}$ aqueous solutions (Chialvo, Cummings et al., 1996) we focused on the dissociation of $\mathrm{HCl}$, a crucially important hydrothermal system whose properties at high temperatures and low densities are still the matter of debate (Chialvo, Cummings et al., 2000). For this purpose we have developed a special implementation of constrained molecular dynamics, based on the 'blue moon ensemble' and its 'constraint-force' equivalent counterpart.

In Figure 2 we display a comparison between our own conductance experimental data and the corresponding simulation results. Our simulation results indicated that the Gertner-Hynes (Gertner and Hynes, 1998) HCl model predicted the association

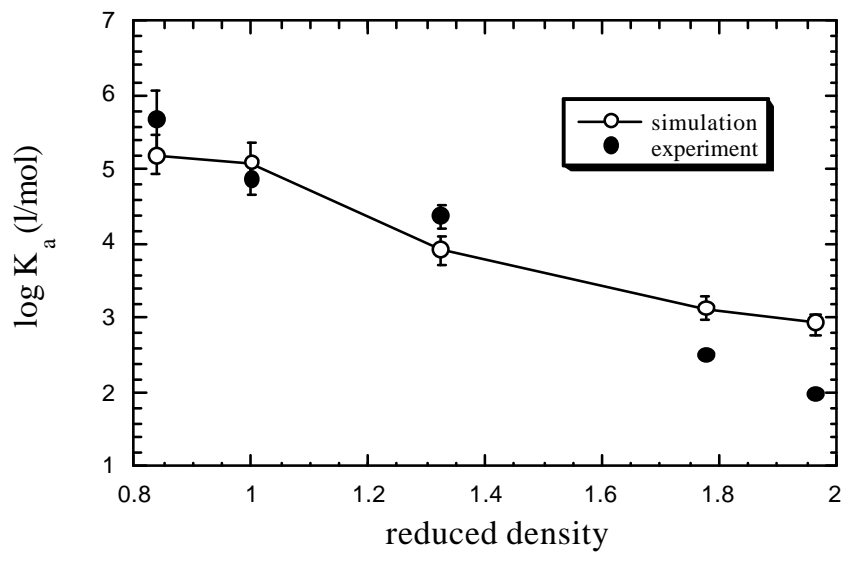

Figure 3. Comparison between experimental data (Ho, Palmer et al., 2001) and simulation results for the association constant of aqueous $\mathrm{HCl}$ at high temperature (Chialvo, Ho et al., 2001). constant within the combined uncertainties of the most reliable experimental data (Franck, 1956; Tagirov, Zotov et al., 1997; Ho, Palmer et al., 2000). Additional simulations (Figure 3) clearly 
showed that the Gertner-Hynes model was able to predict rather accurately the association constant at near critical conditions, i.e., at conditions where experiments are more challenging to perform (Chialvo, Ho et al., 2001). However, at higher densities the simulations gradually overpredict the association constant.

It is clear from these studies that molecular-based approaches hold promise for developing reliable descriptions of solution properties across wide ranges of temperature, particularly in the near-critical region where properties show large and rapid changes with changes in temperature and pressure. Further work in this area is in progress in a number of research groups, both in extending these approaches to solutions of finite concentration and in applying the guidelines established through the solvation formalism to the development of parametric models for solution properties.

\section{Volumetric Properties of C-O-H-N Fluids}

In addition to electrolyte solutes as discussed above, HTO process streams will contain at various points significant concentrations of "noncondensible" gases. If air is used as the oxidizer in the process the predominant gases will be oxygen and nitrogen; as the oxidation of organic constituents of the waste proceeds to completion at high temperatures significant concentrations of $\mathrm{CO}_{2}$ will be present in the fluid. The formation of two fluid phases (gas + liquid) at high temperatures can significantly affect both mass and heat transfer during HTO processing (Kochan and Oh, 1993), and accurate representation of process conditions requires that the fluid density and phase relationships be known accurately at high temperatures. In this project a unique, high pressure vibrating-tube densimeter was used to determine the densities, excess molar volumes, and liquid-vapor phase relations in the system $\left(\mathrm{CO}_{2}+\mathrm{N}_{2}+\mathrm{H}_{2} \mathrm{O}\right)$ at closely spaced intervals of pressure $(P)$ and mole fraction $(X)$ at temperatures from 300 to $400^{\circ} \mathrm{C}$ and pressures to 1000 bars. The new experimental results from these studies, coupled with precise representation of the results based on literature data for the pure fluids (Seitz and Blencoe, 1999; Blencoe et al., 1999; Blencoe et al., 2000), has resulted in a much better knowledge of the phase behavior and volumetric properties of these systems than has previously been available.

The experimental results are characterized by varying ranges of fluid immiscibility and wide variation in values of the excess molar volume;
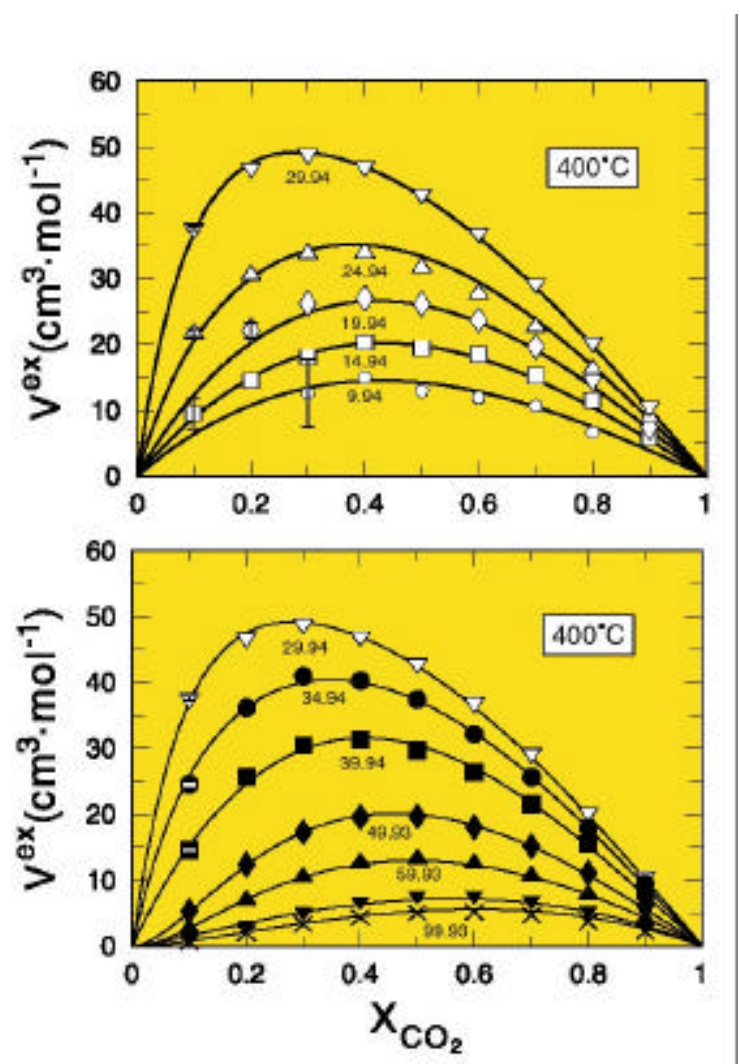

Figure 4. Excess molar volumes for $\left\{\mathrm{H}_{2} \mathrm{O}+\mathrm{CO}_{2}\right\}$ at $400^{\circ} \mathrm{C}$ (Seitz and Blencoe, 1999; Blencoe et al., 1999). i.e., the nonideality of the fluid mixture. At supercritical temperatures (e.g., $400^{\circ} \mathrm{C}$ ) the fluids are miscible over the full range of mole 


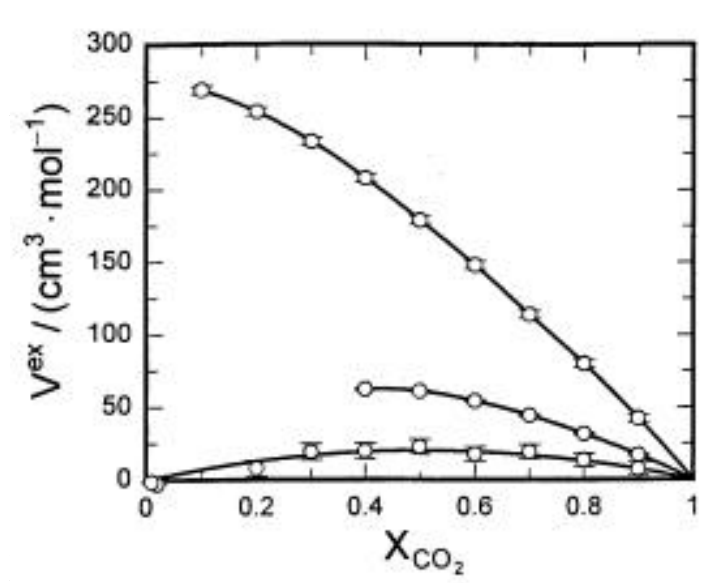

Figure 6. Excess molar volumes for $\mathrm{H}_{2} \mathrm{O}-\mathrm{CO}_{2}$ mixtures at $300^{\circ} \mathrm{C}$ and 74 (bottom), 99 (top) and 199 bars pressure.

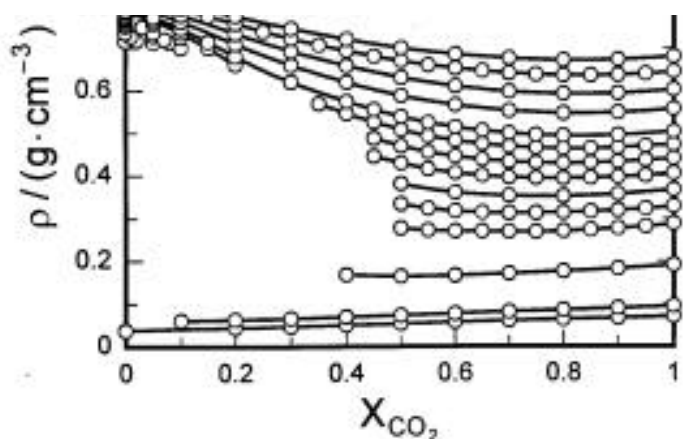

Figure 5. Measured densities for $\mathrm{H}_{2} \mathrm{O}-\mathrm{CO}_{2}$ mixtures at $300^{\circ} \mathrm{C}$. Pressures range from 74 bars (bottom curve) to 1000 bars (top curve).

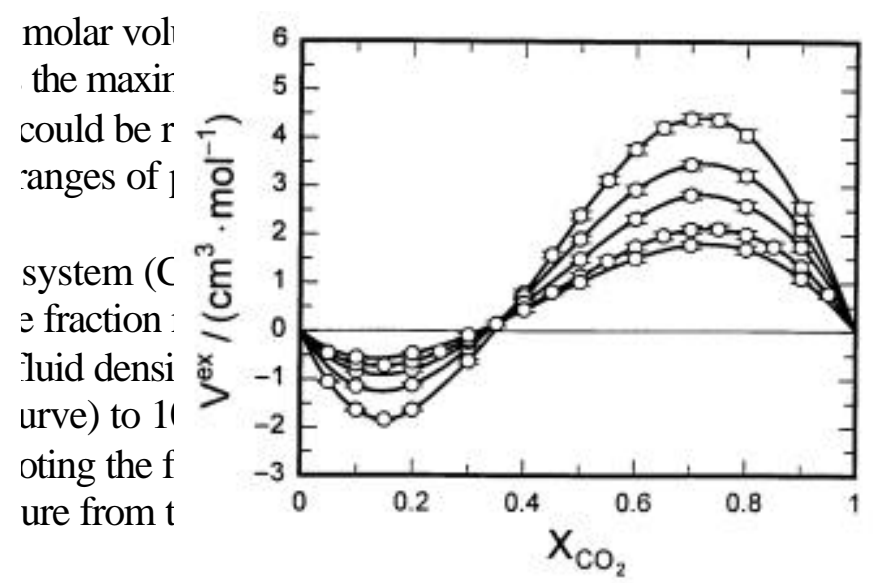

For CO Figure 7. Excess mo lar volumes for $\mathrm{H}_{2} \mathrm{O}-\mathrm{CO}_{2}$ mixtures at pressures from 599 to 999 bars (top coexistel right to bottom right curves). composi could be made at pressures from 86 to 565 bars. Nevertheless, the following characteristics of the data are evident. At low pressures, fluid density increases slowly and continuously from $X_{\mathrm{CO}_{2}}=0$ to $X_{\mathrm{CO}_{2}}=1$. Density vs. $X_{\mathrm{CO}_{2}}$ is nearly linear at 74-199 bars (lowest three curves of figure 5), but distinctly concave upward at higher pressures. At 74 bars, excess molar volume $\left(V^{\mathrm{ex}}\right)$ vs. $X_{\mathrm{CO}_{2}}$ (figure 6) is nearly symmetric, with a peak value of $\sim 20 \mathrm{~cm}^{3} / \mathrm{mol}$ at $X_{\mathrm{CO}_{2}}=0.5$. With increasing pressure from 74 to 99 bars, $V^{\text {ex }}$ vs. $X_{\mathrm{CO}_{2}}$ becomes highly asymmetric

toward $\mathrm{H}_{2} \mathrm{O}$, with a peak excess molar volume of $\sim 270 \mathrm{~cm}^{3} / \mathrm{mol}$ at $X_{\mathrm{CO}_{2}}=0.1$. This value is about $80 \%$ of the molar volume of the mixture, indicating extreme nonideality of the fluid. At higher pressures (figure 7) the excess volumes are smaller, and show both positive and negative departures from ideal mixing depending on fluid composition.

For $\mathrm{N}_{2}-\mathrm{H}_{2} \mathrm{O}$ fluids at this temperature the field of liquid-vapor stability (two-phase mixture) is much more extensive than it is in the $\mathrm{CO}_{2}-\mathrm{H}_{2} \mathrm{O}$ system, widening with increasing pressure up to $>100 \mathrm{MPa}$. The results also indicate that, at a given pressure, the effects of composition on density are more linear for $\mathrm{N}_{2}$-rich $\mathrm{N}_{2}-\mathrm{H}_{2} \mathrm{O}$ mixtures than for $\mathrm{CO}_{2}$-rich $\mathrm{CO}_{2}-\mathrm{H}_{2} \mathrm{O}$ fluids. Excess molar volumes for homogeneous $\mathrm{N}_{2}-\mathrm{H}_{2} \mathrm{O}$ mixtures at $300^{\circ} \mathrm{C}, 74-999$ bars, are similar in magnitude and composition dependence to those determined for $\mathrm{CO}_{2}-\mathrm{H}_{2} \mathrm{O}$ fluids.

\section{Studies of Neutralizer Solubilities and Solids Deposition}

Most DOE aqueous wastes that could be treated using HTO technology contain inorganic materials (e.g., oxides or salts). In addition, corrosion problems may arise from oxidation of organic waste components containing heteroatoms (e.g., sulfur or chlorine). Each of these issues makes it important to consider the solubility of inorganic materials as functions of temperature under HTO process conditions. In the first case, inorganic materials present in the original waste 
may precipitate as the process temperature changes, leading potentially to deposition and fouling of reactor components (Styrikovich, 1976). Precipitation of common salts under HTO process conditions have been studied in some detail (cf. Armellini and Tester, 1991). However, the anticipated presence of actinides in some DOE wastes raises questions as to the fate of these materials under HTO process conditions. Given the oxidizing conditions anticipated in HTO processing we focused our investigations on the solubility of uranium VI compounds at elevated temperatures.

A number of techniques were applied to these solubility studies. In a rapid-quench method, solid samples were equilibrated with solutions at temperature in sealed quartz tubes. After rapid cooling to room temperature liquid samples were removed from the tubes and analyzed for total uranium concentration. It was found that this method gave inconsistent results due to relatively rapid dissolution of the quenched solid in the solution and to difficulties in quantitative segregation of all solid material from the liquid sample. Gold-bag experiments, where solids are equilibrated with solution inside a flexible (gold foil) container within an autoclave at high temperature, were hindered by the same problems of solid separation even when fine frits were used in the sample lines. Best results were obtained with an in situ spectroscopic method, in which uranium concentrations in solution were monitored continuously at temperature by optical spectroscopy. However, the relatively low sensitivity of this method made it impossible to carry out quantitative measurements at higher temperatures where total uranium concentrations in solution dropped below detection limits.

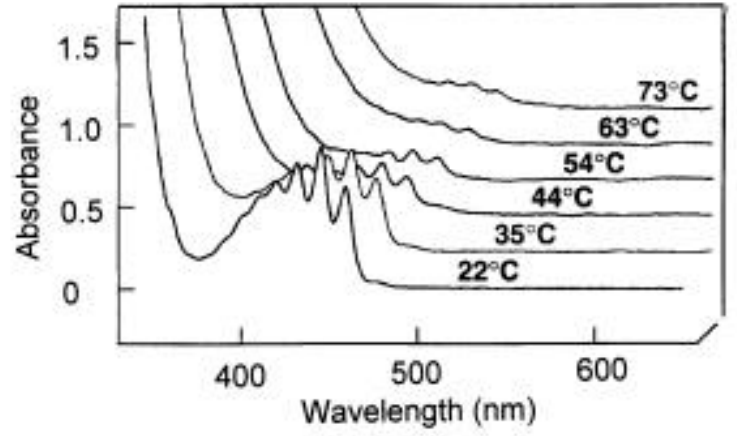

Figure 8. Absorbance spectra from equilibrations of $\mathrm{Na}_{4} \mathrm{UO}_{2}\left(\mathrm{CO}_{3}\right)_{3}$ with aqueous (carbonate + bicarbonate) buffer solutions.

Solubility experiments were carried out in (carbonate + bicarbonate) aqueous buffer media, reflecting the likely presence of carbonates in the process stream arising from reactions of $\mathrm{CO}_{2}$ with basic aqueous solutions. Experiments began with well-characterized uranium oxide $\left(\mathrm{UO}_{3}\right.$, cr). Reproducible results obtained to $100^{\circ} \mathrm{C}$ indicated decreasing solubility of $\mathrm{UO}_{3}$ with increasing temperature. At higher temperatures it was clear that conversion of the solid material to a more stable crystalline form occurred, based on observed variations in uranium concentration in solution as a function of time at temperature. Assuming that the new solid phase was a uranyl carbonate, crystalline samples of $\mathrm{UO}_{2} \mathrm{CO}_{3}$ and $\mathrm{Na}_{4} \mathrm{UO}_{2}\left(\mathrm{CO}_{3}\right)_{3}$ (sodium uranate) were synthesized and characterized by Fourier transform infrared spectroscopy (FTIR) and X-ray diffraction. Good results on the solubility of $\mathrm{Na}_{4} \mathrm{UO}_{2}\left(\mathrm{CO}_{3}\right)_{3}$ were obtained at temperatures to $\sim 100^{\circ} \mathrm{C}$ as indicated by the absorbance spectra shown in figure 8. Again with this salt at higher temperatures, conversion to a second solid phase was indicated by both the trends in total uranium concentration as a function of time and by post-equilibration analysis of recovered solid by FTIR spectroscopy.

While definitive results for the solubility of uranium oxide and carbonate solids were difficult to obtain at elevated temperatures due to solids interconversion on relatively long (to 1.5 months) 
time scales, it is clear from our measurements that the solubility of uranium in these solutions was decreasing with increasing temperature. Further careful studies including the effects of precipitation kinetics will be required to give full confidence that uranium-bearing solids would not precipitate in localized deposits in operating HTO systems as temperature is increased during waste processing.

The second issue concerning solid solubilities under HTO conditions involves compounds that may be added to inhibit corrosion by acids formed on oxidation. In general, the direct addition of caustic (sodium hydroxide) causes significant problems in HTO operation due to caustic corrosion at high temperatures, and other neutralizers are desirable. The alkali metal and alkaline earth carbonates are attractive for this application, in that reactions of these treatment chemicals with $\mathrm{CO}_{2}$ produced in the oxidation of organic wastes results in a buffered solution of

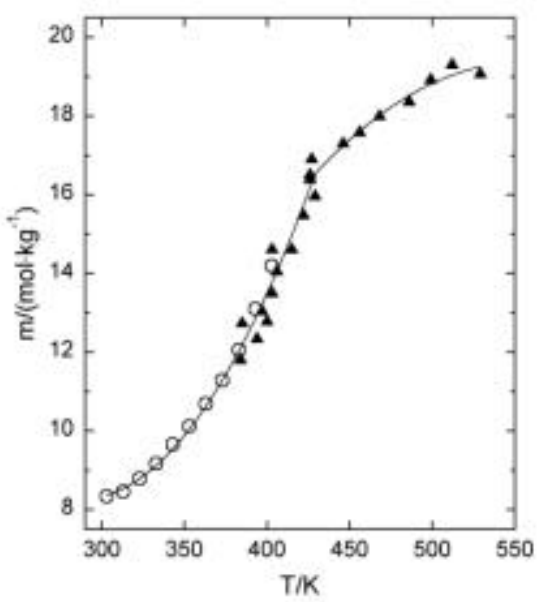

Figure 9. Solubility of $\mathrm{K}_{2} \mathrm{CO}_{3}$ in water as a function of temperature (Moore et al., 1997). carbonate and bicarbonate in a desirable range of $\mathrm{pH}$.

However, sodium carbonate shows a sharp increase in solubility between 25 and $c a .100^{\circ} \mathrm{C}$, then steadily decreases in solubility, with relatively low solubility above $300^{\circ} \mathrm{C}$ where corrosion protection is most needed. The solubility of potassium carbonate was investigated as a potential replacement for the sodium salt in HTO neutralizer applications.

These measurements were carried out using the synthetic method with visual detection of the temperature at which all solid $\mathrm{K}_{2} \mathrm{CO}_{3}$ disappeared from the cell. It was not possible to reverse these measurements (i.e., approach equilibrium from supersaturation) due to extensive supersaturation of these solutions followed by immediate crystallization of

a large mass of solid. In addition, caustic attack of the sapphire windows used in the visuallyaccessible cell made it impossible to extend these measurements above $\sim 250^{\circ} \mathrm{C}$. However, it is clear from figure 9 that the solubility of $\mathrm{K}_{2} \mathrm{CO}_{3}$ continues to increase at high temperatures, making this salt a good candidate for further studies as an in situ neutralizers under HTO process conditions. Further work at high temperatures along the lines described by Armellini and Tester (1991) is needed to assess the practicality of this neutralization method in operating HTO systems.

\section{Relevance, Impact, and Technology Transfer}

The scientific focus of this program has centered on the mitigation of DOE aqueous hazardous and mixed waste through understanding and improving the applicability of hydrothermal oxidation technology for treating these wastes. While the ultimate application of these results to DOE waste remediation technologies depends on future deployment decisions, this work is supportive of the future option for HTO. In particular, if it is determined that HTO is a desirable alternative to incineration in situations where it may not be desirable to use incineration to meet 
DOE compliance requirements (e.g., INEEL), work such as that reported here will contribute to the selection process for alternative technologies.

Hydrothermal oxidation technology is not scheduled for immediate deployment to address major DOE waste management issues. The scope of this work was designed to bridge the gap between fundamental studies of the properties of aqueous systems at high temperatures and pressures and the actual process conditions anticipated in a future deployment of HTO technology. These results will be used by investigators with specific interests in HTO applications, and in broader applications of DOE environmental technology including actinide speciation and migration and issues of carbon management in power cycles. While additional efforts in this area are clearly desirable in support of the option of future HTO deployment, large-scale or intensified efforts in the near future will depend on the process of selecting appropriate alternatives to incineration.

Through this project significant advances have been made in our understanding of molecularlevel processes driving the remarkable behavior of aqueous fluid mixtures and solutions at high temperatures. We have also made steps toward understanding the complex phase behavior of uranium salts and oxides at elevated temperatures, and have delineated with high precision the high-temperature phase boundaries and volumetric properties of aqueous fluid mixtures. Spectroscopic techniques for phase behavior at elevated temperature developed in this project show promise for future studies of the solubility of complex solids. The new formalism for nearcritical properties of aqueous solutions will contribute to future developments of more accurate representations of solution properties under conditions where earlier models have severe limitations. These advances have contributed to our broader understanding of solution properties at high temperatures and have opened new avenues for future research contributions from project collaborators and other scientists working in the field of solution chemistry under extreme conditions.

Fundamentally, the application of the results of this project to DOE Environmental Management problems depends on a decision to further develop or deploy HTO technology to treat aqueous mixed wastes. Further studies of the phase behavior and thermodynamic properties of specific materials within candidate wastes will be required; the scope of these future studies will depend on the composition of the wastes identified for treatment by this technology. In the near term, the U.S. Army is moving toward deployment of HTO technology for the destruction of chemical agent stockpiles and other applications. The PI for this project was invited by Dr. Robert Shaw of the Army Research Office to participate in a workshop specifically targeted to issues of phase behavior under HTO process conditions (see Publications, below).

\section{Project Productivity}

The overall scientific productivity of this project is reflected in the listing of publications and presentations given below, with sixteen papers published in the refereed literature. In addition, a number of presentations and published proceedings resulted from the project, and additional publications of research results are anticipated. Two areas of the anticipated experimental work did not proceed as rapidly as anticipated and remain of interest for future studies. The slow kinetics of dissolution and precipitation of uranyl salts, coupled with their low solubility at 
elevated temperature, precluded rapid progress in that work. Corrosion problems in delivering fluids with high oxygen fugacity caused us to focus efforts in PVT studies on non-oxygenated mixtures, and complementary work with added oxygen remains to be carried out for a more complete description of high-temperature fluid properties.

\section{Personnel Supported}

\begin{tabular}{|l|l|l|}
\hline Investigator & Institution & Position \\
\hline J. M. Simonson & ORNL & Scientific staff \\
\hline R. E. Mesmer & ORNL & Scientific staff \\
\hline J. G. Blencoe & ORNL & Scientific staff \\
\hline S. Dai & ORNL & Scientific staff \\
\hline J. Singh & ORNL & Postdoctoral fellow \\
\hline A. A. Chialvo & ORNL/UT* & Collaborating Scientist \\
\hline P. T. Cummings & UT/ORNL** & Distinguished Scientist \\
\hline
\end{tabular}

*Collaborating Scientist in the Chemical and Analytical Sciences Division of Oak Ridge National Laboratory and the Department of Chemical Engineering, University of Tennessee

**Distinguished Professor of Chemical Engineering, University of Tennessee, and Distinguished Scientist, Chemical Technology Division, Oak Ridge National Laboratory

\section{Publications}

Publications in peer-reviewed journals

Anovitz, L. M., J. G. Blencoe, D. B. Joyce, and J. Horita (1998) "Precise Measurements of the Activity/Composition Relations of $\mathrm{H}_{2} \mathrm{O}-\mathrm{CO}_{2}$ and $\mathrm{H}_{2} \mathrm{O}-\mathrm{N}_{2}$ Fluids at $500^{\circ} \mathrm{C}, 500$ Bars," Geochim. Cosmochim. Acta 62, 1998, 815-829.

Seitz, J. C. and J. G. Blencoe (1999) "The $\mathrm{H}_{2} \mathrm{O}-\mathrm{CO}_{2}$ System. I. Experimental Determination of Volumetric Properties at $400^{\circ} \mathrm{C}$ and 10-100 MPa," Geochim. Cosmochim. Acta 63, 1999, 1559-1569.

Blencoe, J. G., J. C. Seitz, and L. M. Anovitz (1999) “The $\mathrm{H}_{2} \mathrm{O}-\mathrm{CO}_{2}$ System. II. Calculated Thermodynamic Mixing Properties for $400^{\circ} \mathrm{C}, 0.1-400 \mathrm{MPa}$," Geochim. Cosmochim. Acta 63, 1999, 2393-2408.

Chialvo, A. A., P. T. Cummings, J. M. Simonson, and R. E. Mesmer (1997) "Molecular Simulation Study of Speciation in Supercritical Aqueous $\mathrm{NaCl}$ Solutions," Journal of Molecular Liquids 73-74: 361-372.

Chialvo, A. A. and P. T. Cummings (1998) "Simple Transferable Intermolecular Potential for the Molecular Simulation of Water over Wide Ranges of State Conditions," Fluid Phase Equilibria 155-151: 73-81.

Chialvo, A. A., P. T. Cummings, and Yu. V. Kalyuzhnyi (1998) "Solvation Effects on Kinetic Rate Constant of Reactions in Supercritical Solvents," AICHE J. 44: 667-680. 
Chialvo, A. A., P. T. Cummings, J. M. Simonson, and R. E. Mesmer (1998) “Thermodynamics and Kinetics of Ion Speciation in Supercritical Aqueous Solutions. A Molecular-based Study," Fluid Phase Equilibria 150-151: 107-115.

Chialvo, A. A. and P. T. Cummings (1999) "Molecular-based Modeling of Water and Aqueous Solutions at Supercritical Conditions." Advances in Chemical Physics. S. A. Rice, ed. New York, Wiley \& Sons. 109: 115-205.

Chialvo, A. A., P. T. Cummings, J. M. Simonson, and R. E. Mesmer (1999) "Solvation in HighTemperature Aqueous Electrolyte Solutions," Journal of Molecular Liquids 87, 233-242. Chialvo, A. A., P. T. Cummings, J. M. Simonson, and R. E. Mesmer (1999) "Solvation in HighTemperature Electrolyte Solutions. I. Hydration Shell Behavior from Molecular Simulation," Journal of Chemical Physics 110: 1064-1074.

Chialvo, A. A., P. T. Cummings, J. M. Simonson, and R. E. Mesmer (1999) "Solvation in HighTemperature Electrolyte Solutions. II. Some Formal Results,” Journal of Chemical Physics 110: 1075-1086.

Chialvo, A. A., P. G. Kusalik, P. T. Cummings, and J. M. Simonson (2000) "Molecular Approach to High-Temperature Solvation. Formal, Integral Equation, and Experimental Results," Journal of Physics. Condensed Matter 15: 3585-3594.

Chialvo, A. A., P.T. Cummings, and J. M. Simonson (2000) " $\mathrm{H}_{3} \mathrm{O}^{+} / \mathrm{Cl}^{-}$Ion Pair Formation in High-Temperature Aqueous Solutions,” Journal of Chemical Physics 113, 8092-8100. Chialvo, A. A., P. G. Kusalik, P. T. Cummings, and J. M. Simonson (2001) "Solvation in HighTemperature Electrolyte Solutions. III. Integral Equation Calculations and Interpretation of Experimental Data," Journal of Chemical Physics 114, 3575-3585.

Dai, S., M. C. Burleigh, J. M. Simonson, R. E. Mesmer, and Z.-L. Xue, (1998) “Application of Chemometric Methods in UV-Vis Absorption Spectroscopic Studies of Uranyl Ion Dimerization Reaction in Aqueous Solutions", Radiochimica Acta 81, 195-199.

Moore, R. C., R. E. Mesmer, and J. M. Simonson (1997). "Solubility of Potassium Carbonate in Water between 384 and 529 K Measured Using the Synthetic Method," J. Chem. Eng. Data 42, 1078-1081.

Publications in Conference Proceedings (peer reviewed)

Blencoe, J. G., Anovitz, L. M. and Seitz, J. C. (1998) "A Helmholz Free Energy Model for Supercritical $\mathrm{H}_{2} \mathrm{O}-\mathrm{CO}_{2}$ Mixtures," Geol. Soc. Amer. Abs. with Prog., V. 30, p. A-319. Singh, J., Blencoe, J. G., and Seitz, J. C. (1998) "Experimentally Determined Excess Molar Volumes for $\mathrm{H}_{2} \mathrm{O}-\mathrm{N}_{2}$ Fluids at $300^{\circ} \mathrm{C}, 75-1000$ Bars," Geol. Soc. Amer. Abs. with Prog., V. 30, p. A-319.

Blencoe, J. G., L. M. Anovitz, and J. Singh (2000) "A Semi-Empirical Excess Pressure Equation for $\mathrm{CO}_{2}-\mathrm{H}_{2} \mathrm{O}$ Fluids at $400^{\circ} \mathrm{C}, 0-400 \mathrm{MPa}$," Proceedings of the 13th International Conference on the Properties of Water and Steam, P. R. Tremaine, P. G. Hill, D. E. Irish and P. V. Balakrishnan, eds. Ottawa, Canada: NRC Research Press, pp. 126-133.

Singh, J., J. G. Blencoe, and L. M. Anovitz (2000) "Volumetric Properties and Phase Relations of Binary $\mathrm{H}_{2} \mathrm{O}-\mathrm{CO}_{2}-\mathrm{CH}_{4}-\mathrm{N}_{2}$ Mixtures at $300^{\circ} \mathrm{C}$ and Pressures to 1000 Bars," Proceedings of the 13th International Conference on the Properties of Water and Steam, P. R. Tremaine, P. G. Hill, D. E. Irish and P. V. Balakrishnan, eds. Ottawa, Canada: NRC Research Press, pp. 134-143.

Anovitz, L. M., T. C. Labotka, J. G. Blencoe, J. Singh, and J. Horita (2000) "Experimental Determination of the Activity-Composition Relations and Phase Equilibria of $\mathrm{H}_{2} \mathrm{O}-\mathrm{CO}_{2}-$ 
$\mathrm{NaCl}$ Fluids," Proceedings of the 13th International Conference on the Properties of Water and Steam, P. R. Tremaine, P. G. Hill, D. E. Irish and P. V. Balakrishnan, eds. Ottawa, Canada: NRC Research Press, pp. 207-214.

Chialvo, A. A., P. T. Cummings, J. M. Simonson, and R. E. Mesmer (2000) "Ion Association in

High-Temperature Aqueous HCl Solutions. A Molecular Simulation Study," Proceedings of the 13th International Conference on the Properties of Water and Steam, P. R. Tremaine, P. G. Hill, D. E. Irish and P. V. Balakrishnan, eds. Ottawa, Canada: NRC Research Press, pp. 409-417.

Chialvo, A. A., P. T. Cummings, P. G. Kusalik, J. M. Simonson, and R. E. Mesmer, "HighTemperature Solvation in Aqueous Electrolyte Solutions. Formal, Integral Equation, and Experimental Results," Proceedings of the 13th International Conference on the Properties of Water and Steam, P. R. Tremaine, P. G. Hill, D. E. Irish and P. V. Balakrishnan, eds. Ottawa, Canada: NRC Research Press, pp. 517-524.

\section{Selected Presentations}

Anovitz, L. M., Labotka, T. C., Blencoe, J. G., Singh, J., and Horita, J. 'Experimental Determination of the Activity-Composition Relations and Phase Equilibria of $\mathrm{H}_{2} \mathrm{O}-\mathrm{CO}_{2}$ $\mathrm{NaCl}$ Fluids," 13th ICPWS, Toronto, Ontario, 1999.

Blencoe, J. G., Anovitz, L. M., and Singh, J. "A Semi-Empirical Excess Pressure Equation for $\mathrm{CO}_{2}-\mathrm{H}_{2} \mathrm{O}$ Fluids at $400^{\circ} \mathrm{C}, 0-400 \mathrm{MPa}$, " 13th ICPWS, Toronto, Ontario, 1999.

Chialvo, A. A., P. T. Cummings, et al. "High-temperature Solvation in Aqueous Electrolyte Solutions. Formal, Integral Equations, and Experimental Results," 13th ICPWS, Toronto, Ontario, 1999.

Chialvo, A. A., P. T. Cummings, et al. "Ion Association in High-Temperature Aqueous HCl Solutions. A Molecular Simulation Study," 13th ICPWS, Toronto, Ontario, 1999.

Singh, J., Blencoe, J. G., and Anovitz, L. M., "Volumetric Properties and Phase Relations of Binary $\mathrm{H}_{2} \mathrm{O}-\mathrm{CO}_{2}-\mathrm{CH}_{4}-\mathrm{N}_{2}$ Mixtures at $300^{\circ} \mathrm{C}$ and Pressures to 1000 Bars," 13th ICPWS, Toronto, Ontario, 1999.

Dai, S., J. M. Simonson, and R. E. Mesmer "Solubility of $\mathrm{Na}_{4} \mathrm{UO}_{2}\left(\mathrm{CO}_{3}\right)_{3}$ in aqueous solutions at high temperature", 215th National ACS Meeting, Dallas, March 1998.

Chialvo, A. A., P.T. Cummings, J.M. Simonson, and R.E. Mesmer, "Solvation in Supercritical

Electrolyte Solutions. Formal and Experimental Results," Invited talk at the 215th National ACS Meeting, Dallas, March 1998.

Simonson, J. M. "Phase Equilibria and Thermodynamics in High Temperature Aqueous Systems," Guide-lines for Phase Separations in High Temperature and Supercritical Water Solutions, workshop sponsored by the Army Research Office, Forschungzentrum Karlsruhe, Germany, 7-10 July 1999.

Results to be published

Blencoe, J. G., M. T. Naney, and L. M. Anovitz, "The $\mathrm{CO}_{2}-\mathrm{H}_{2} \mathrm{O}$ system. III. A New Experimental Method for Determining Liquid-Vapor Equilibria at High Subcritical Temperatures," Amer. Mineral., submitted for publication.

Dai, S. and J. M. Simonson (2001) "High-temperature UV-VIS spectra of uranium carbonate complexes," in preparation. 
Moore, R. C., and J. M. Simonson (2001) "The Solubility of (Potassium Carbonate + Potassium Chloride) and (Potassium Carbonate + Potassium Bicarbonate) in Water at High Temperatures," in preparation.

Singh, J., J. G. Blencoe, J. C. Seitz, M. T. Naney, and L. M. Anovitz, "Experimentally

Determined Densities and Excess Molar Volumes for $\mathrm{N}_{2}-\mathrm{H}_{2} \mathrm{O}$ Fluids at $300^{\circ} \mathrm{C}$ and Pressures to $100 \mathrm{MPa}$," in preparation.

Chialvo, A. A., P. C. Ho, et al. (2001). " $\mathrm{H}_{3} \mathrm{O}^{+} / \mathrm{Cl}^{-}$Association in Hydrothermal Systems. A Direct Comparison between Simulation Results and Conductance Measurements," in preparation.

\section{Interactions}

Participation of project personnel in meetings and other interactions has been detailed above. In addition, the project PI participated with detailed posters describing project results at two EMSP workshops (Chicago, 1998; Atlanta, 2000). Expertise arising from this program and from projects at Oak Ridge National Laboratory sponsored by the DOE BES Division of Chemical Sciences, Geosciences and Biosciences led to and invitation for the project PI to participate in the workshop Guide-lines for Phase Separations in High Temperature and Supercritical Water Solutions, sponsored by the Army Research Office at Forschungzentrum Karlsruhe, Germany, 710 July 1999. The purpose of this workshop was to address operating guidelines for operating conditions for HTO systems expected to be applied to U.S. Army demilitarization applications. In addition, results from this program were communicated to the wider scientific community in an invited presentation at the American Chemical Society National Meeting in Dallas, TX, in March 1998.

\section{Transitions}

The primary transition to date of project results with direct application to HTO waste remediation technology occurred through participation in the guideline-establishing Army Research Office workshop detailed above.

\section{Patents}

As the primary goal of this project was to provide needed scientific information in support of future technology deployment decisions, no inventions or patent disclosures resulted from the work.

\section{Future Work}

The scope of future work in this area will depend to some extent on the identification of DOE wastes to be treated by hydrothermal oxidation. While significant advances in understanding aqueous fluids and phase behavior under anticipated process conditions have been made in this 
work, additional studies and pilot-scale testing will be required for actual wastes to be treated. In particular, further information is needed on the phase behavior of aqueous fluid mixtures containing oxygen or other oxidizers, to reflect pre-reaction process fluid compositions, and on the solubilities of inorganic solids (particularly actinide oxides and related materials) at elevated temperature in solutions which reflect the chemical composition of the aqueous waste to be treated.

\section{Literature Cited}

Anderko, A. and K. S. Pitzer (1993) "Equation-of-state Representation of Phase Equilibria and Volumetric Properties of the System $\mathrm{NaClH}_{2} \mathrm{O}$ above $573 \mathrm{~K}$," Geochim. Cosmochim. Acta 57, 1657-1680.

Armellini, F. J. and J. W. Tester (1991) "Experimental Methods for Studying Salt Nucleation and Growth from Supercritical Water," Proceedings of the $2^{\text {nd }}$ International Symposium on Supercritical Fluids, Boston, MA, 20-22 May 1991.

Blencoe, J. G., J. C. Seitz, and L. M. Anovitz (1999) “The $\mathrm{H}_{2} \mathrm{O}-\mathrm{CO}_{2}$ System. II. Calculated Thermodynamic Mixing Properties for $400^{\circ} \mathrm{C}, 0.1-400 \mathrm{MPa}$," Geochim. Cosmochim. Acta 63, 2393-2408.

Chialvo, A. A. and P. T. Cummings (1994) "Solute-induced Effects on the Structure and the Thermodynamics of Infinitely Dilute Mixtures," AICHE J. 40: 1558-1573.

Chialvo, A. A., P. T. Cummings, et al. (2000) "High-Temperature Solvation in Aqueous

Electrolyte Solutions. Formal, Integrals Equations and Experimental Results," Steam, Water, and Hydrothermal Systems: Physics and Chemistry Meeting the Needs of Industry.

P. G. H. P. Tremaine, D. Irish, P.V. Balakrishnan. Ottawa, NRC Research Press: 517-524.

Chialvo, A. A., P. T. Cummings, et al. (2000) " $\mathrm{H}_{3} \mathrm{O}^{+} / \mathrm{Cl}$ Ion Pair Formation in High-

Temperature Aqueous Solutions," Journal of Chemical Physics 113: 8093-8100.

Chialvo, A. A., P. T. Cummings, et al. (1996) "Temperature and Density Effects On The High

Temperature Ionic Speciation in Dilute $\mathrm{Na}^{+} / \mathrm{Cl}^{-}$Aqueous Solutions," Journal of Chemical Physics 105: 9248-9257.

Chialvo, A. A., P. T. Cummings, et al. (1999) "Solvation in High-Temperature Electrolyte

Solutions. II. Some Formal Results," Journal of Chemical Physics 110: 1075-1086.

Chialvo, A. A., P. T. Cummings, et al. (2000) "Ion Association in High-Temperature Aqueous

$\mathrm{HCl}$ Solutions. A Molecular Simulation Study," Steam, Water, and Hydrothermal

Systems: Physics and Chemistry Meeting the Needs of Industry. P. G. H. P. Tremaine, D.

Irish, P.V. Balakrishnan. Ottawa, NRC Research Press: 409-417.

Chialvo, A. A., P. C. Ho, et al. (2001). " $\mathrm{H}_{3} \mathrm{O}^{+} / \mathrm{Cl}$ Association in Hydrothermal Systems. A

Direct Comparison between Simulation Results and Conductance Measurements,"

Manuscript in preparation.

Chialvo, A. A., P. G. Kusalik, et al. (2000) "Molecular Approach to High-Temperature

Solvation. Formal, Integral Equations, and Experimental Results,' Journal of Physics.

Condensed Matter 12: 3585-3593.

Chialvo, A. A., P. G. Kusalik, et al. (2001). "Solvation in High-Temperature Electrolyte

Solutions. III. Integral Equation Calculations and Interpretation of Experimental Data,"

Journal of Chemical Physics 114: 3575-3585. 
Franck, E. U. (1956) "Hochverdichteter Wasserdampf - III Ionendissoziation von HCl, KOH und $\mathrm{H}_{2} \mathrm{O}$ in überkritischem Wasser," Zietschr. Phys. Chemie N.F. 8: 192-206.

Gertner, B. J. and J. T. Hynes (1998) "Model molecular dynamics simulation of hydrochloric acid ionization at the surface of stratospheric ice," Faraday Discussions 110: 301-322.

Gruszkiewicz, M. S. and R. H. Wood (1997) "Conductance of $\mathrm{LiCl}, \mathrm{NaCl}, \mathrm{NaBr}$, and $\mathrm{CsBr}$ Solutions in Supercritical Water Using a Flow Conductance Cell,' Journal of Physical Chemistry B 101: 6549-6559.

Ho, P. C., D. A. Palmer, et al. (2000) "Conductivity Measurements of Dilute HCl Solutions to High Temperatures and Pressures Using a Flow-through Cell," Journal of Physical Chemistry 105: 1260-1266.

Kochan, R. J. and C. H. Oh (1993) Preliminary Analytical Modeling Requirements for Thermal Hydraulic Analysis of SCWO Pilot Plant, Idaho National Engineering Laboratory Report EGG-WTD-10985, November 1993.

Moore, R. C., R. E. Mesmer, and J. M. Simonson (1997). "Solubility of Potassium Carbonate in Water between 384 and 529 K Measured Using the Synthetic Method," J. Chem. Eng. Data 42, 1078-1081.

Pitzer, K. S., J. C. Peiper and R. H. Busey (1984) "Thermodynamic Properties of Aqueous Sodium Chloride Solutions," J. Phys. Chem. Ref. Data 13, 1-102.

Seitz, J. C. and J. G. Blencoe (1999) "The $\mathrm{H}_{2} \mathrm{O}-\mathrm{CO}_{2}$ System. I. Experimental Determination of Volumetric Properties at $400^{\circ} \mathrm{C}$ and 10-100 MPa," Geochim. Cosmochim. Acta 63, 1999, 1559-1569.

Styrikovich, M. A. (1976) "Scale Formation and Deposition from High Temperature Aqueous solutions," in High Temperature High Pressure Electrochemistry in Aqueous Solutions, NACE-4, D. de G. Jones and R. W. Staehle, eds. Houston: National Association of Corrosion Engineers, p. 195.

Tagirov, B. R., A. V. Zotov, et al. (1997) "Experimental Study of Dissociation of $\mathrm{HCl}$ from 350 to $500^{\circ} \mathrm{C}$ and 500 to 2500 bars. Thermodynamic Properties of $\mathrm{HCl}^{\circ}(\mathrm{aq}), "$ Geochim. Cosmochim. Acta 61: 4267-4280.

Thomason, T. B. and M. Modell (1984) "Supercritical Water Destruction of Aqueous Wastes," Hazardous Waste 1, 453.

Wood, R. H. (1997) Personal communication during the 5th. International Symposium on Hydrothermal Reactions (ISHR'97). 